\title{
External Sources of Clean Technology: Evidence from the Clean Development Mechanism*
}

\author{
Patrick Bayer ${ }^{\dagger}$ \\ University of Mannheim
}

\author{
Johannes Urpelainen \\ Columbia University
}

13 August 2012

\begin{abstract}
New technology is fundamental to sustainable development. However, inventors from industrialized countries often refuse technology transfer because they worry about reverse-engineering. When can clean technology transfer succeed? We develop a formal model of the political economy of North-South technology transfer. According to the model, technology transfer is possible if (i) the technology in focus has limited global commercial potential or (ii) the host developing country does not have the capacity to absorb new technologies for commercial use. If both conditions fail, inventors from industrialized countries worry about the adverse competitiveness effects of reverse-engineering, so technology transfer fails. Data analysis of technology transfer in 4,894 projects implemented under the Kyoto Protocol's Clean Development Mechanism during the 2004-2010 period provides evidence in support of the model.
\end{abstract}

${ }^{*}$ This paper was written during a research stay funded by an ERP fellowship of the Studienstiftung des deutschen Volkes. Patrick Bayer gratefully acknowledges this generous funding and is thankful for the hospitality of Columbia University. We thank Christopher Marcoux for help with data collection and management. We also thank Thomas Hale, Richard Perkins, Eri Saikawa, and two anonymous reviewers for helpful comments on a previous draft.

${ }^{\dagger}$ Corresponding author. Department of Political Science, University of Mannheim. D7, 27. 68131 Mannheim, Germany. Phone: +49-621-181-2418. Email: pbayer@mail.uni-mannheim.de 


\section{Introduction}

New technology is the cornerstone of economic growth (Grossman and Helpman, 1991). If developing countries are to increase their standards of living, they must gain access to advanced technologies that increase productivity. In addition to enhancing productivity, advanced technologies can help developing countries combat negative externalities, such as air pollution (Mani and Wheeler, 1998). Given that rapid industrialization has created new pollution problems, including climate change, and increased the consumption of natural resources, the current economic trajectory of many large developing countries, such as China and India, is not sustainable. However, enhancing sustainability in these countries requires the introduction of new advanced technologies. Without new technology, sustainability can only be achieved by reducing economic growth, which seems both politically infeasible and normatively unwarranted in light of how many people continue to live in poverty in these countries.

Against this backdrop, the importance of international technology transfer is paramount. Unfortunately, concerns about competitiveness, and reverse-engineering in particular, often discourage innovators from providing developing countries with advanced technologies (Maskus, 2000; Gallagher, 2006). If innovators provide advanced technologies to firms in developing countries, these firms or their local competitors can apply reverse-engineering to enhance their competitiveness in global markets. Concerns about reverseengineering are closely related to developing countries' rapid industrialization, their increasing relevance as economic competitors in manufacturing industries (Lewis, 2007), and the thorny issue of property rights (Ockwell et al., 2010).

What, then, are the conditions under which transfers of clean technology are feasible? With some exceptions (Dechezleprêtre, Glachant, and Ménière, 2008; Perkins and Neumayer, 2009), scholars of sustainable development have made surprisingly little progress toward understanding the conditions that allow technology transfer from industrialized to developing countries. While the international dimension of sustainability is commonly acknowledged (Ward, 2006), and the policy importance of technology transfer is widely recognized (Hoekman, Maskus, and Saggi, 2005; Brewer, 2008), there are few political-economic theories on the promotion of technology transfer in different conditions, not to mention the dearth of empirical evidence.

Building on these ideas, we examine the conditions that allow international technology transfer. Specif-

ically, we analyze a comprehensive dataset on technology transfer in the Kyoto Protocol's Clean Develop- 
ment Mechanism (CDM). The CDM allows project developers to profit from implementing projects that reduce carbon dioxide emissions in developing countries. While the CDM's emphasis is on cost-effective climate mitigation, another stated goal of the CDM is to promote the transfer of clean technology from industrialized to developing countries (UNFCCC, 2010). Overall, the CDM's record of technology transfer is impressive: our data show that approximately one third of all CDM projects feature technology transfer. Many CDM projects focus on modern renewable sources, such as solar and wind, so CDM projects can tell us about technology transfer more generally. We theorize about the circumstances that allow, and disallow, technology transfer. To test the theory, we examine the determinants of technology transfer in 4,894 CDM projects during the years 2004-2010.

Both formally and empirically, we show that technology transfer is difficult when the following two conditions are met. First, the technology in focus is key to export competitiveness in global markets. Second, the recipient country's capacity to absorb new technologies is high. Our data show that if both conditions are met at the same time, innovators from industrialized countries are unwilling to transfer new technologies to developing countries.

This article offers two main contributions to scholarship on the international dimensions of sustainable development. First, ours is the first study that analyzes competitiveness concerns in technology transfer using detailed data on individual projects. Given the increasing importance of technology transfer in international political economy, this article breaks new ground, opening a window of opportunity for a dynamic research program on the general problem of transferring advanced technology in a global North-South context. Building on our insights, future research could examine technology transfer in other contexts, such as foreign direct investment and development projects funded by the World Bank and other multilateral agencies.

Second, this article shows both the value and limits of technology transfer. Countries with high absorptive capacity may expect less transfer of commercially valuable technologies than countries with low absorptive capacity. The good news is that technology transfer benefits countries that need it the most. The bad news is that countries most capable of adopting new technologies benefit less, and the problem is pronounced for the most valuable technologies.

The findings also suggest ways to improve the design of international institutions for technology trans- 
fer. If concerns about future competition are a central impediment to technology transfer, then international institutions, including the CDM, should offer subsidies and other incentives to inventors who transfer new technologies to rapidly industrializing countries. Moreover, while international institutions cannot remove concerns about competitiveness, they can help inventors design contracts and programs that allow technology transfer while controlling reverse-engineering. Given these two opportunities, the CDM could use some of the revenue from carbon credits to subsidize technology transfer while offering technical and legal assistance to the design of technology transfer contracts.

\section{The International Political Economy of Technology Transfer}

By technology transfer, we refer to the transmission of production methods and know-how from one country to another (Saggi, 2002). This definition of technology transfer covers a wide range of goods and services. Moreover, it covers both tangible equipment and intangible knowledge. While our empirical analysis focuses on environmental technology, our theory is intended to apply to technology transfer in a more general sense.

Technology transfer is essential for development, and this is so for at least two reasons. First, economic growth requires productivity enhancement, and few developing countries are able to enhance their productivity significantly without access to foreign technology. According to Keller (2004, 742), "[f]or most countries, foreign sources of technology account for 90 percent or more of domestic productivity growth." Second, new technologies can help developing countries combat negative externalities. For example, if developing countries gain access to clean technology, they can reduce their environmental burden even under economic growth (Perkins and Neumayer, 2009).

While technology transfer is beneficial to developing countries, there are multiple obstacles to it. Owners of advanced technology often refuse technology transfer because they worry about loss of competitive advantage. This problem is chronic for countries that are unable to protect the intellectual property rights of foreign investors (Maskus, 2000). For example, Gallagher (2006) finds that American automobile manufacturers have reduced their technology transfer to China because they worry about reverse-engineering. Indeed, governments of rapidly industrializing countries, such as China and India, frequently emphasize international competitiveness as a key rationale for subsidizing new technologies (Lewis and Wiser, 2007; Ockwell et al., 2010). Moreover, many developing countries lack the ability to exploit advanced technolo- 
gies (Keller, 1996).

Despite a broad consensus on the importance and difficulty of technology transfer, the international political economy thereof remains poorly understood. Although there is some qualitative evidence for the political salience of technology transfer in North-South negotiations (Ockwell et al., 2010), social scientists have yet to develop analytical models of the political economy of technology transfer, let alone test such models against quantitative data. The lack of theoretical progress and empirical evidence prevents scholars and policymakers from understanding the political-economic determinants of technology transfer. In turn, this lack of understanding raises impediments to effective policy interventions and strategies. In what follows, we begin to address the problem by developing a formal model of technology transfer and test it against data on technology transfer in the Kyoto Protocol's CDM.

In the literature on CDM, technology transfer now plays an important role. Although technology transfer is not a formally stated requirement of the CDM, many developing countries have emphasized the importance of technology transfer. According to the literature (Dechezleprêtre, Glachant, and Ménière, 2008; UNFCCC, 2010), technology transfer is particularly common in large projects implemented in rapidly growing developing countries that have already reached relatively high levels of technological prowess, in some cases through previous CDM project implementation. Moreover, the literature suggests that the CDM promotes technology transfer through multiple channels, including institutional support and enhanced commercial viability of clean technology projects (Schneider, Holzer, and Hoffmann, 2008). Our primary contribution to this literature is a theoretical and empirical analysis of interactive effects between the technology's commercial value and the recipient country's absorptive capacity: we show that countries with high absorptive capacity receive advanced, commercially important renewable energy technologies less often than countries with low absorptive capacity. However, there is no such effect for non-renewable energy technologies. While this interactive effect has not been recognized in previous research, our theoretical and empirical analysis below shows that it is fundamental to understanding North-South transfers of clean technology under the CDM. 


\section{A Theory of Clean Technology Transfer}

The purpose of our theory is to explain variation in technology transfer from technologically advanced to less advanced countries. The unit of analysis is a project. We define a project as a profitable investment opportunity.

We assume the project's value depends partly on technology transfer. If the project is implemented with advanced technology, not available in the host country, the project's profitability increases. This profitability may reflect both commercial value, such as a decreased implementation cost, and the enhanced supply of global public goods, which an international institution may implicitly reward.

In our theory, we consider the incentives of two players: a project developer and a technology inventor. The project developer is a firm in the host country. The technology inventor is a foreign firm that owns an advanced technology. We investigate the determinants of whether the project developer can cooperate with the technology inventor to gain access to advanced technology.

Even though technology transfer is potentially profitable, it may fail. The technology inventor worries that if it transfers advanced technology, the project developer uses the advanced technology to enhance its competitiveness outside the specific project. For example, a Chinese wind turbine manufacturer could illegally reverse-engineer a German blade design, without compensating the German technology inventor. This would reduce the German technology inventor's competitiveness in global markets.

\subsection{Model}

Our theory does not focus on the upstream decision to implement projects, so we begin with the premise that the project is already under consideration. This assumption is based on the idea that, for most projects, technology transfer is not a "make or break" decision. Instead, it is a decision that determines the size of the rents from the project. Therefore, the inventor must now decide whether to transfer an advanced technology to increase the profitability of the project. Let $T \in\{0,1\}$ denote the transfer decision. The game tree is provided in Figure 1.

[Figure 1 about here.] 
Without loss of generality, the project's value is normalized to zero without technology transfer. If technology transfer occurs, the project generates one unit of profits. These profits are divided between the inventor and developer. We allow any division of profits between the two players, and we assume this division of profits can be determined ex ante. In practice, the division of profits would be implemented through a contract on the technology license. As in the game tree above, let $x \in[0,1]$ denote the inventor's share of the profits, and note that $1-x$ is thus the project developer's share of the profits.

If technology transfer occurs, the project developer must decide whether to use the advanced technology outside the project. We refer to such usage as "reverse-engineering," formally $R \in\{0,1\}$. Such usage is assumed to be costly to the inventor. The project developer must pay a cost $C>0$ to reverse-engineer the technology. This cost reflects factors such as hiring engineers and designers to learn how to build the advanced foreign technology, as well as the cost of avoiding being caught by the foreign inventor. We assume that the project developer itself implements the reverse-engineering only for concreteness: our strategic model holds even if the reverse-engineering is done by a third party, such as a local competitor. ${ }^{1}$

The project developer's cost of reverse-engineering, $C$, depends on a variety of factors, including intellectual property rights. In countries with stringent patent laws, reverse-engineering results in legal sanctions, such as fines. Thus, while our theory focuses on absorptive capacity and commercial value, it seems intuitive that reverse-engineering would be less common in countries that impose demanding standards on intellectual property rights.

The value of reverse-engineering the technology is $A V$, where $A>0$ measures the project developer's absorptive capacity and $V>0$ measures the commercial value of the advanced technology in global markets. Importantly, the relationship between the two is assumed to be multiplicative. As the technology's value $V$ increases, the importance of absorptive capacity also increases. This is intuitive: absorptive capacity is not valuable unless the technology in focus holds considerable commercial promise.

Absorptive capacity is a complex phenomenon. According to Keller $(1996,200)$, the absorptive capacity of a country or a company can be generally defined as the availability of skills to "implement technologies invented abroad ... [which] requires that more skills must be built up by domestic workers and managers." In our model, absorptive capacity is defined in terms of the project developer's skills and knowledge. This

\footnotetext{
${ }^{1}$ Formally, this can be seen by simply relabeling the "project developer" as a "third party" and reiterating the equilibrium analysis. Equilibrium behavior remains unchanged.
} 
absorptive capacity is positively associated with the project developer's size, availability of capital and skilled labor in the host country economy, and the management's technological competence. If the project developer has achieved a level of technological sophistication that allows it to reverse-engineer the advanced foreign technology, and then use the reverse-engineering to enhance its own productivity, then $A$ acquires a high value.

The cost of reverse-engineering to the inventor is $L(V)>0$, where $L$ is some strictly increasing function of $V$. This intuitive assumption states that as the technology's value $V$ increases, the inventor's cost of losing it to a competitor also increases.

\subsection{Equilibrium}

The game has a sequential structure, so the appropriate solution concept is the subgame-perfect Nash equilibrium (SPNE). Our simple game can be solved via backward induction. First, we examine whether the project developer has an incentive to reverse-engineer an available technology. Second, given the project developer's equilibrium strategy, we examine whether the technology inventor is willing to transfer.

In equilibrium, the project developer reverse-engineers an available technology whenever $A V>C$ : the expected benefits, which are given by the product of absorptive capacity and the value of the technology, must exceed the cost of reverse-engineering the technology.

Next, we characterize the inventor's best response in the strategically prior decision to transfer technology. First, suppose $A V \leq C$ so that the project developer would not reverse-engineer. In this case, the inventor clearly transfers because the technology is not threatened. Second, suppose $A V>C$ so that the project developer would reverse-engineer. Recall that profits can be divided between the inventor and the developer: $x \in[0,1]$. In the formal model, the technology inventor transfers the technology if and only if $L(V)<1$. In this case, a distribution of profits $\left(x^{*}, 1-x^{*}\right)$ exists such that the technology inventor is willing to transfer, even though the technology is ultimately reverse-engineered.

\subsection{Testable Hypotheses}

The model generates hypotheses on the project developer's absorptive capacity, the advanced technology's value, and their interactive effect. This section summarizes these hypotheses. To foreshadow, we find that 
technology transfer is particularly difficult to countries with high absorptive capacity in the case of advanced and commercially valuable technologies.

First, consider the effect of absorptive capacity. All else constant, we find that increased absorptive capacity undermines technology transfer.

Hypothesis 1 (absorptive capacity). As the project developer's absorptive capacity $A$ increases, the likelihood of technology transfer decreases.

As soon as absorptive capacity reaches the critical threshold of $A=\frac{C}{V}$, the project developer begins to reverse-engineer the technology. Therefore, the inventor's incentive to transfer the technology decreases. ${ }^{2}$

In practice, changes in absorptive capacity may be followed by other changes, such as new rules for intellectual property rights. Indeed, a host country could attempt to enhance intellectual property rights, so as to continue technology transfer despite enhanced absorptive capacity. In the empirical analysis, we need to account for this. ${ }^{3}$

Second, consider the technology's value. As the technology's commercial value increases, it is intuitive that the technology inventor would become less willing to transfer.

Hypothesis 2 (value of technology). As the advanced technology's value $V$ increases, the likelihood of technology transfer decreases.

Valuable technologies are not easy to transfer, and this is so for two reasons. First, valuable technologies encourage the project developer to reverse-engineer. Second, the loss from losing the monopoly of a valuable technology is particularly large.

Finally, and most importantly, consider the interactive effect. We find that the negative effects of absorptive capacity and technology value reinforce each other.

Hypothesis 3 (interactive effect). The negative effect of increasing the advanced technology's value $V$ on the likelihood of technology transfer grows in size as the project developer's absorptive capacity $A$ increases.

\footnotetext{
${ }^{2}$ Empirically, absorptive capacity could also reduce technology transfer simply because there is less need for advanced technology. The empirical analysis accounts for this.

${ }^{3}$ It is important not to overestimate the importance of this concern. All members of the World Trade Organization have committed to implementing the Agreement on Trade Related Intellectual Property Rights, which increases the homogeneity of intellectual property rights across member states, regardless of their absorptive capacity.
} 
This hypothesis is key to testing our model. By noting that technology transfer is the least likely when the recipient country has high absorptive capacity and the technology at hand has considerable commercial value, we can examine the explanatory power of our model.

\section{Research Design}

To test the theory, we need data on projects implemented in a large number of potential recipient countries. Moreover, these projects need to hold potential for technology transfer. If we can find a dataset of such projects, we can examine whether host country characteristics and technology type have the hypothesized interactive effects on technology transfer.

We use data on technology transfer in 4,894 CDM projects implemented in the years 2004-2010. ${ }^{4}$ Designed to reduce the cost of abating carbon dioxide emissions, the CDM allows project developers to implement projects in developing countries and earn carbon credits for them. ${ }^{5}$ During project implementation, project developers can acquire advanced environmental technologies from their partners in industrialized countries. This practice of technology transfer can reduce the cost of emissions reductions. However, partners from industrialized countries may not transfer technologies if they worry about reverse-engineering and other learning effects that have adverse consequences for their competitiveness.

Two features of the CDM allow us to test our interactive hypothesis. First, there are different types of CDM projects. Some are based on renewable energy, an industry that is expected to boom in the future. Others, such as afforestation or agricultural methane emissions, require technologies with much less commercial potential in the future. This difference allows us to examine the importance of technological value, formally $V$. Second, CDM projects have been implemented in dozens of different countries. Some countries hold large amounts of wealth, and this wealth provides them with the capacity to develop globally competitive industries based on technology transfer. Variation in host country characteristics allows us to identify absorptive capacity, formally $A$.

While the CDM is not perfectly representative of the much broader canvas of clean technology transfer, it is noteworthy that CDM projects do cover a wide variety of common clean technologies. In the online

\footnotetext{
${ }^{4}$ See http: //cdm.unfCCC.int/about/CDM_TT/index.html. Accessed on March 2, 2012.

${ }^{5}$ See the online appendix for a more detailed description of the CDM.
} 
appendix, we provide an inclusive list of CDM project types, and provide descriptive statistics for projects under them. This list shows that the CDM has resulted in the implementation of a wide variety of climate mitigation projects, and that technology transfer has also occurred across the board. Thus, much can be learned from analyzing CDM projects.

There are two further barriers to credible inference that require attention. First, CDM projects are not a random sample of possible projects. This selection issue, which is common in the study of environmental politics (Ringquist and Kostadinova, 2005), can be addressed by controlling for how attractive each host country is for CDM projects. Countries that implement many CDM projects could systematically differ from other countries, and a control for propensity to implement CDM projects allows us to correct for this bias. Second, endogeneity may be an issue, as previous research shows that technology transfer allows learning (UNFCCC, 2010). Controlling for previous CDM projects also helps here, as it corrects for possible bias from a history of project implementation that would allow learning. Of course, the inclusion of time trends and country fixed effects also helps with regard to selection and endogeneity.

\subsection{Dependent Variable}

Our dependent variable is a binary indicator for technology transfer. For a project that features technology transfer, it equals 1 . For all other projects, it equals 0 . In the dataset, the number of projects that feature technology transfer is 1,458 , or $30 \%$ of all 4,894 projects.

The data on technology transfer are based on project design documents and were collected by the CDM team of the UNFCCC. The CDM team reviewed the project documents of all available CDM projects for evidence concerning the transfer of technological knowledge and/or equipment (UNFCCC, 2010). If such evidence was found, the project was coded as featuring technology transfer. If no evidence was found, the project was coded as not featuring technology transfer. This is a conservative coding rule because it is possible that some projects feature technology transfer without mentioning it in the project documents. In the online appendix, we also examine alternative coding rules.

To illustrate the coding, consider the following examples. In October and December 2006, respectively, two biomass energy projects were registered for implementation in Hebei, a Chinese province. One of the projects, titled "Jinzhou 24MW Straw-Fired Power Project," explicitly states in the project design document 
that it does not feature any technology transfer. ${ }^{6}$ The other, titled "Hebei ChengAn Biomass Cogeneration Project," imported clean technology from the Danish BWE Company: ${ }^{7}$

"The technology employed by the proposed project is from Denmark BWE, where the key components of the boiler fired with local straw (130t/h in capacity) in the proposed project are imported. A technology transfer activity therefore will be involved through the implementation of the proposed project."

More examples of the coding can be found in the online appendix.

\subsection{Independent Variables}

To explain technology transfer in CDM projects, we rely on two main independent variables and their interaction term. Project type is used to capture the value of the technology transferred, while the recipient's GDP represents absorptive capacity. Though these proxies are somewhat crude, they capture our essential theoretical concepts. Moreover, an extensive robustness analysis allows us to reject plausible alternative explanations for our findings.

First, we record the project's type. This variable is binary, and it distinguishes between renewable energy and other project types. Renewable energy is one of the most rapidly growing global industries, so transfers of renewable energy technology hold high commercial value, $V$. In the main analysis, we apply a broad definition of renewable energy. Consistent with the definition of the Intergovernmental Panel on Climate Change (IPCC), we define technology transfer as a "broad set of processes covering the flows of know-how, experience and equipment for mitigating and adapting to climate change amongst different stakeholders, such as governments, private sector entities, financial institutions, non-governmental organizations (NGOs) and research/ education institutions" (UNFCCC, 2010, 13).

Although most of these technologies are being rapidly developed, hydroelectricity presents some complications. While most of the extant hydroelectricity installations do not require any advanced technologies, new installations can also rely on new technologies to reduce environmental burden, generate electricity

\footnotetext{
${ }^{6}$ See http: / / cdm. unfCcC. int/UserManagement/FileStorage/5GNJ1LAV6C1G3Y01QJJ5XS4CZ4GVDO for the project design document. Accessed on March 12, 2012.

${ }^{7}$ See http: / / cdm. unfCcC. int/UserManagement/FileStorage/JO5PY7U6ZW4 9C2BX3K8RMTADQ1 HLEN for the project design document. Accessed on March 12, 2012.
} 
in locations that were previously uneconomical, and so forth. In the online appendix, we thus also report analyses that exclude all hydroelectricity installations. Similarly, we report results from an analysis without energy efficiency technologies, a non-renewable project type with some commercial promise.

The global market for renewable technologies has been rapidly growing for the last decade or so (REN21, 2011). Between the years 2000 and 2010, global wind power capacity increased from 17.4 gigawatts to 198 gigawatts, more than a 10 -fold increase. At the same time, global solar photovoltaics capacity increased from 1.4 gigawatts to 40 gigawatts, almost a 30 -fold increase, while the production of ethanol and biodiesel increased from less than 18 billion to approximately 105 billion liters. Many other renewable energy technologies, ranging from small hydroelectricity installations to geothermal power, also expanded. ${ }^{8}$ Overall, total investment in renewable energy reached USD 211 billion in 2010.

First and foremost, the fast expansion of capacity has been driven by stupendous decreases in the cost of renewable electricity generation. In addition to the rapid growth of renewable electricity markets, these technologies are valuable because they can be used in a wide variety of contexts. For example, wind power relies on certain basic technologies, such as turbine blades. ${ }^{9}$ Each such technology can be sold to booming global markets, so losing the technology to a competitor would be costly to the extreme. In contrast, other key technologies transferred under the CDM are more specific. Most major energy conservation projects are intended for a specific industrial installation, and the technologies used there may not travel well to other contexts. Cement projects focus on a specific industry, and the technologies used in them cannot be used in other industries. Agricultural methane avoidance projects, which play an important role in the CDM, also do not depend on technologies that can be commercialized for a wider range of uses. In light of these observations, it is appropriate to assume that the technology's commercial value, $V$, is on average much higher for renewables than for other technologies.

The rapid growth of renewable energy makes it an important "strategic good" (Goenner, 2010). As societies seek sustainable and reliable alternatives to conventional fossil fuels, renewable energy is at the forefront. Energy is a basic requirement for all economic activity, and energy prices have recently been

\footnotetext{
${ }^{8}$ Unfortunately, we do not have the 2000 and 2010 numbers for all major sectors of renewable electricity generation. Concentrating solar thermal power increased from 355 to 1,095 megawatts between 2007 and 2010. Growth was slower for geothermal power and hydropower. Since hydropower is a major CDM sector, we also estimated our model without hydropower projects.

${ }^{9}$ While hydroelectricity (1,362 projects) and wind projects (921 projects) account for more than $75 \%$ of all renewable projects, biomass projects (636 projects) also make up a considerable part of total renewable CDM projects.
} 
high due to rapidly growing demand. The centrality of energy to economic activity and security means that the renewable energy markets will probably continue to grow rapidly in the long run, further bolstering the argument that the commercial value, $V$, is higher for renewables than for other technologies.

To illustrate the importance of distinguishing between renewable energy and other projects in the empirical analysis, consider Figure 2. It shows that, overall, technology transfer is much less common in renewable than other projects. In many ways, this is surprising: if the profitability of renewable energy is critically dependent on advanced technologies, why is technology transfer so rare, overall? Our theory can explain this puzzling pattern: foreign technology is often not transferred due to concerns about competitiveness, and these are more pronounced for renewable than for non-renewable technologies.

[Figure 2 about here.]

Second, we use the recipient country's logarithmized GDP (USD, 2000 constant prices) as an indicator for absorptive capacity. Large and wealthy countries can better absorb advanced foreign technologies. This measure can be decomposed into two constituent elements. First, it clearly captures a recipient country's per capita wealth. Since productivity is the primary determinant of per capita wealth, this is a simple measure for technological prowess. Second, it captures a recipient country's size. If sufficiently small, even technologically advanced countries often do not present a commercial threat to innovators from industrialized countries. In the developing world, few small countries are able to maintain advanced technology industries on a sufficient scale to conquer global markets. ${ }^{10}$

The data on wind energy technology certainly support these propositions. In early 2010, the Danish company Vestas remained the world's largest wind turbine manufacturer, followed by the American company General Electric. However, the largest gains in recent years have been made by companies from developing countries. World's fourth largest manufacturer was the Indian company Suzlon Energy, while the Chinese companies Goldwind, Sinovel, Dongfang, and Ming Yang Power held the sixth, seventh, and eighth positions, respectively. ${ }^{11}$

While GDP is a country covariate, it is appropriate for testing our theory about the effects of absorptive

\footnotetext{
${ }^{10}$ Indeed, separating between the effects of GDP per capita and population, the composite terms of GDP, does not seem warranted here. GDP per capita should only have a positive effect if population is large, and vice versa.

${ }^{11}$ See "List of Top Wind Power/Turbine Companies/ Stocks - Chinese Rising" at http: //www . greenworldinvestor. com/2011/03/10. Accessed on March 12, 2012.
} 
capacity. A country with a large GDP has many companies that could potentially reverse-engineer new technologies and reach a sufficient scale to become an international competitor to the sender of the technology. The set of companies with the capacity to reverse-engineer should be positively associated with GDP, so we expect renewable energy projects to feature considerably less technology transfer to economically large than to economically small countries. Technically, the coefficient for the interaction term between the renewable project type and logarithmized GDP should be negative.

To illustrate this hypothesis, it is perhaps useful to consider how Chinese and Indian wind turbine manufacturers have improved their technological capabilities. Lewis $(2007,226)$ notes that

"[t]he acquisition of technology from overseas companies is one of the easiest ways for a new wind company to quickly obtain advanced technology and begin manufacturing turbines; however, there is a disincentive for leading wind turbine manufacturers to license proprietary information to companies that could become competitors. This is particularly true for technology transferred from developed to developing countries, where a similar technology potentially could be manufactured in a developing country with less expensive labor and materials, resulting in an identical but cheaper turbine."

Building on this logic, she shows that both the Indian company Suzlon and the Chinese company Goldwind were unable to license the most advanced and reliable technologies from the leading manufacturers, such as the Danish company Vestas. Instead, Suzlon and Goldwind had to rely on smaller Western manufacturers whose technologies had yet to accumulate as much actual user experience.

Given that GDP is directly related to the size of a developing country's population, in the online appendix we also examine models that interact renewable project type with population. Given our focus on absorptive capacity, our theory predicts that GDP should be a much better prediction of technology transfer than population. Empirically, we indeed find that GDP is a more accurate predictor of technology transfer than population. This suggests that our focus on absorptive capacity is warranted.

Another potential problem with the GDP variable is that it may capture the lack of need for foreign technology. To account for this, the online appendix presents models that interact renewable project type with the country's renewable energy patent count and electricity generation capacity. In both cases, GDP continues to be an accurate predictor. This suggests that access to domestic technology cannot explain the 
effects we find, so that we can rule out an important alternative explanation.

While we prefer GDP as a more comprehensive measure of absorptive capacity, it is true that GDP also captures other dimensions of economic development (Hendrix, 2010). In an extensive robustness analysis, we consider and reject various alternative explanations, but we acknowledge that our empirical analysis cannot exactly identify the causal mechanism through which GDP modifies the differences in technology transfer between renewable and non-renewable projects. As an alternative to GDP, we also estimated our models using total counts for international patents approved under the 1976 Patent Cooperation Treaty. By verifying that the main results hold for total patent counts as well, we can alleviate this concern. ${ }^{12}$

For illustration, consider Table 1. It provides a list of the 20 leading recipients. For each recipient, we computed the proportions of renewable energy projects and all other projects that featured technology transfer. For the three leading recipients (China, India, Brazil), technology transfer was much less common for renewable than other projects. This is consistent with our theoretical expectation.

\section{[Table 1 about here.]}

The table offers another important lesson: many of the technologically advanced countries in the sample had to rely on technology transfer. Israel, which is hardly a developing country, imported technology in all five of its renewable projects and in $77 \%$ of its non-renewable projects. Similarly, Chile imported technology in $51 \%$ of its 37 renewable projects, and in $53 \%$ of its 32 non-renewable projects. These patterns are not consistent with the idea that high levels of productivity are enough to reduce technology transfer.

\subsection{Control Variables}

We present a parsimonious and theoretically informed specification for our empirical analysis; the online appendix presents an extensive robustness analysis. To begin with, all of our models include a cubic time polynomial to control for time trends. ${ }^{13}$ Since the need for technology transfer may decline over time, it is essential to account for temporal patterns (UNFCCC, 2010).

\footnotetext{
${ }^{12}$ When both GDP and patents are included, the effects of GDP are generally stronger than the effects of patents. Qualitatively, however, both variables have the expected effects.

${ }^{13}$ Since time fixed effects induce bias in limited dependent variable models, as Beck, Katz, and Tucker (1998) and Chamberlain (1980) show, we opt for a specification with a cubic time polynomial (Carter and Signorino, 2010). We are thankful to one of the reviewers for pointing this out.
} 
We also account for project size, as the transaction cost of implementing technology transfer for small projects may be prohibitive. According to previous research, small projects indeed feature less technology transfer than large projects (Dechezleprêtre, Glachant, and Ménière, 2008). The CDM classifies some projects as "small," so we include a binary indicator for smallness.

The CDM allows project developers to implement projects regardless of a formal contract with a partner from an industrialized country (Michaelowa, 2007). On average, it appears plausible that contracts with a partner from an industrialized country feature technology transfer more often than other projects. Therefore, we include a binary indicator for whether the project was "unilateral" in that the project did not, at the time of registration with the CDM, have an advance contract for the expected carbon credits. ${ }^{14}$

According to previous research, learning effects play an important role in CDM technology transfer (UNFCCC, 2010). We include the cumulative number of CDM projects, separately for renewables and non-renewables, that a country registers over the years. To avoid conflating learning with country size, we normalize these CDM project numbers by a country's total carbon dioxide emissions. ${ }^{15}$ In the online appendix, we also verify that our results hold if we use the current number of CDM projects for each year instead of cumulative counts. Notably, including the cumulative or current number of CDM projects also accounts for a particularly important endogeneity issue: countries that have already secured many projects have less need for technology transfer from new projects. Similarly, this control accounts for selection issues across countries, as it distinguishes between more and less attractive CDM hosts.

To account for other country characteristics, we also include a control variable for corruption. CDM projects carry high transaction costs, so a corrupt bureaucracy could raise impediments to technology transfer. Thus, accounting for corruption is useful. We rely on the International Country Risk Guide's measure. ${ }^{16}$ This variable ranges from 0 to 6 , with higher values indicating more corruption. In the online appendix, we also demonstrate the robustness of our results to the inclusion of other country characteristics, such as democracy, population, and the protection of intellectual property rights.

Since CDM host countries may differ considerably across each other, and controlling for all this het-

\footnotetext{
${ }^{14}$ The variable is coded by the CDM/JI Pipeline Database. The measure does not distinguish between projects that had, and had not, a foreign partner at the very beginning. We also cannot follow the formation of partnerships at later stages since our data for technology transfer are from the time of registration. For other definitions of unilateral projects, see Lütken and Michaelowa (2008).

${ }^{15}$ The data for carbon dioxide emissions are from the World Bank's World Development Indicators.

${ }^{16}$ See http: / / www.prsgroup. com/ICRG. aspx. Accessed on March 2, 2012.
} 
erogeneity proves difficult, we implement a fixed effects model to avoid omitted variable bias. By doing so, we preclude estimating model coefficients based on variation across countries. Given dramatic variation in economic growth rates across key developing countries, within-country variation suffices to examine our hypotheses, even as the temporal coverage of the sample is limited to seven years, 2004-2010.

To check that our results also survive if we consider variation across countries, some models use random instead of fixed effects. For these models, the error structure is allowed to vary across countries, but more control variables are needed. Additional control variables decrease the likelihood of omitted variable bias in our random effects model. We therefore include the following additional variables: a binary democracy measure from Cheibub, Gandhi, and Vreeland (2010), logarithmized population size, the number of internet users to proxy a country's technological prowess, share of GDP produced by the industrial sector, investment profile, and inward foreign direct investments. We lag all these control variables by one period to avoid losing CDM project data for 2010; all data are taken from the World Bank's World Development Indicators. To control for country differences in demand for technology transfers, we also add three control variables on the logarithmized number of international patents ${ }^{17}$, the number of renewable patents ${ }^{18}$, as well as each country's ranking in Park's (2008) patent protection index.

Summary statistics are provided in Table 2. Correlation matrices are provided in the online appendix. ${ }^{19}$ In addition to the full sample, we provide the summary statistics and correlation matrices for samples without China and India. These subsamples are separately analyzed below to ensure that these leading CDM host countries are not exerting undue influence on the results. ${ }^{20}$ One feature of these descriptive statistics worth discussing is the very high correlation between renewable project type and the interaction term. This is because there is a large number of non-renewable projects, specifically 1,932 . For these projects, both the interaction term and the renewable project type variable score zero. Indeed, the correlation between the interaction term and GDP itself is much lower. This means that we are able to estimate the marginal effect of changing GDP on the probability of technology transfer.

\footnotetext{
${ }^{17}$ The data come from the 1976 Patent Cooperation Treaty, available from the OECD website at http: / / stats.oecd. org/ Index. aspx?DatasetCode=PATS_IPC.. Accessed on April 18, 2012.

${ }^{18}$ See previous footnote for data source.

${ }^{19}$ Summary statistics and correlation matrices are all based on our fixed effects models.

${ }^{20}$ Popp $(2011,147)$ notes that, apart from China, South Korea implemented policies to promote technology transfer. One of our robustness checks in the online appendix, therefore, excludes South Korea as a host country. Our findings are robust to the exclusion of 72 Korean CDM projects.
} 
[Table 2 about here.]

In the online appendix, we also provide a detailed breakdown of project types for China, India, and the rest of the world. In the early years of the CDM, Chinese projects tended to focus on the destruction of trifluoromethane, and these projects were widely regarded as problematic (Wara and Victor, 2008). Our data show this is no longer the case. Today, Chinese and Indian projects are biased toward key issue areas, notably energy conservation and renewable energy. This highlights the CDM's technology transfer potential.

\subsection{Model Specification}

The dependent variable is binary, so we estimate a logistic regression. Our analysis focuses on the interactive effect of host country characteristics and project type. ${ }^{21}$ To avoid omitted variable bias because of unobservable characteristics that vary across host countries, the main model is a conditional fixed effects logit model. This model identifies coefficients based on within-country variation and controls for time-invariant, country-specific factors. Formally, we estimate the following regression:

$$
\operatorname{Logit}(\mathrm{TT})_{i, j}=\alpha+\beta_{1} \mathrm{GDP}_{j, t}+\beta_{2} \operatorname{Renew}_{i, j}+\beta_{3} \mathrm{GDP}_{j, t} \cdot \text { Renew }_{i, j}+\gamma^{\prime} \mathbf{X}_{i, j}+\delta^{\prime} \mathbf{Z}_{j, t}+t+t^{2}+t^{3}+\mu_{j}+\varepsilon_{i, j}
$$

where Logit(TT) $)_{i, j}$ denotes the logit function of technology transfer in the $i$ th project in host country $j, \mathbf{X}$ is a vector of project control variables, $\mathbf{Z}$ is a vector of country control variables, $t, t^{2}, t^{3}$ is the cubic time polynomial, $\mu_{j}$ captures country-fixed effects, and $\varepsilon_{i, j}$ is the error term. The remaining symbols denote coefficients. Our main expectation is that $\beta_{3}$ is negative. We also estimate random effects models to exploit variation across countries.

\section{Findings}

Overall, the empirical analysis supports our primary hypothesis: there is a negative and consistent interactive effect between renewable project type and the recipient's logarithmized GDP. This effect is present both if

\footnotetext{
${ }^{21}$ We acknowledge that testing interactive hypotheses in nonlinear models not necessarily requires interactive product terms in the statistical model specification. Following the recommendation in Berry, DeMeritt, and Esarey (2010), we run likelihood ratio tests for all our main models with and without the interaction term. For all our models, we can reject the null hypothesis that the models with and without interaction term are identical with $p<0.001$.
} 
we only consider within-country variation by implementing conditional fixed effects and if we account for cross-country variation by using random effects instead. We begin by presenting the main results. Next, we report results from our robustness tests.

\subsection{Main Results}

The estimation results are reported in Table 3. Models (1)-(3) do not contain any control variables, while models (4)-(6) include project control variables and the corruption control. Models (7)-(9) present random effect models with the above described extensive set of control variables. Models (2), (5), and (8) exclude China, while models (3), (6), and (9) exclude India. In each model, the coefficient for renewable project type is positive. However, the exact magnitude of this coefficient is meaningless: given the interaction with the logarithmized GDP, the coefficients represent a country that produces nothing (Brambor, Clark, and Golder, 2006). In all nine models, there is also a strong and negative interaction between renewable project type and logarithmized GDP.

\section{[Table 3 about here.]}

As Ai and Norton (2003) and Berry, DeMeritt, and Esarey (2010) demonstrate, a statistically significant interaction effect in nonlinear models is neither a necessary nor a sufficient condition to support an interaction hypothesis on response probabilities. Therefore, we present simulated substantive effects in Figure 3. These simulations are based on model (4) in Table 3, with 10,000 draws from a multivariate normal distribution. We set continuous control variables at their means, while the binary project controls for project size and unilateral implementation are set at their median values. The cubic time polynomial is also set to its median year 2008 .

Since one of the interacting variables, namely the logarithm of the host country's GDP, is continuous, the interactive effect is best illustrated by comparing the probability of technology transfer for renewable and non-renewable projects. To do so, we plot the probability ratio, which is defined as the probability of technology transfer being equal to one for renewable projects divided by the probability of technology transfer being equal to one for non-renewable projects. ${ }^{22}$ This probability ratio is a meaningful quantity of

\footnotetext{
${ }^{22}$ Formally, the probability ratio is given as $\frac{\operatorname{Pr}(\mathrm{TT}=1 \text { |renewables }=1, \mathbf{M})}{\operatorname{Pr}(\mathrm{TT}=1 \text { |renewables }=0, \mathbf{M})}$, where $\mathbf{M}$ is the matrix of all covariates except for the renewable project dummy.
} 
interest as it is independent of a specific baseline and thus comparable across intercepts in our fixed effects models.

Figure 3 below shows that for the lowest GDP values, the probability ratio is clearly greater than one. The probability for technology transfers is much larger for renewable than for non-renewable projects. Since renewable energy requires advanced technologies, small and poor countries often need foreign technology inputs for renewable energy generation. This is intuitive: in the least developed countries, advanced renewable energy technologies are simply not available, so technology transfer is necessary for project implementation.

For the highest GDP values, renewable projects secure much less technology transfer than non-renewable projects. The probability ratio is smaller than one, so probabilities for technology transfer are smaller for renewable than for non-renewable projects. This is consistent with our expectations: as the economies of key developing countries, such as China and India, grow, they secure fewer technology transfers than in the past. Indeed, the superimposed data distribution shows that the vast majority of CDM projects are located in countries where renewable energy projects receive less technology transfer than non-renewable projects.

To further illustrate our findings, we note that countries such as Bangladesh (25.02), Bhutan (20.25), Guatemala (23.97), Liberia (20.07), and Nicaragua (22.39) show probability ratios larger than one, while China (28.62), India (27.42), Indonesia (26.23), Mexico (27.27), and South Africa (25.94) consistently demonstrate probability ratios smaller than one. For the latter group of countries, technology transfers are estimated to be less likely for renewable than for non-renewable projects, while the opposite pattern holds true for the first set of countries.

[Figure 3 about here.]

These results cannot be attributed to the lack of need to transfer technology. If this was the case, then we would expect host countries with large GDP values to obtain new technologies neither for renewable nor for non-renewable projects. But this is not the case. Empirically even the two largest countries, China and India, frequently import advanced technologies for non-renewable projects. However, they rarely import technology for renewable energy technologies.

The control variables also contain interesting insights. As the cumulative number of non-renewable projects implemented in the host country increases, the probability of technology transfer decreases. This 
suggests that learning effects exist: if technology transfer has already occurred in previous projects, it is no longer needed in new projects within a given country. For renewable energy projects, the evidence is weaker.

The models also provide support for the hypothesis that project size is important. Small projects feature less technology transfer than large projects, and the effect is consistent across our models. The evidence for the role of unilateral versus bilateral implementation is weaker, as our results are not robust to excluding India. This lack of robustness may, however, reflect the difficulty of measuring the actual degree of cooperation between developing and industrialized country partners.

Country covariates are also important. Most importantly, industrial production and a good investment profile are positively associated with technology transfer, while actual inward investment flows are negatively associated with it. This latter finding may reflect the possibility that FDI results in technological development at earlier stages, and this means that there is less need for explicit technology transfer under the CDM.

Overall, the results provide evidence for our model: since renewable energy technologies hold considerable commercial potential, they do not benefit from technology transfer as much as other projects do. While GDP is a somewhat crude proxy for absorptive capacity, it is safe to say that expansion of economic activity is not conducive to foreign technology transfers. This pattern is normatively unfortunate given the importance of advanced technology for the profitability of renewable energy. However, the underlying economic incentives are clear.

\subsection{Additional Tests}

The empirical results are robust to various changes in the specification, as reported in the online appendix. Inclusion of additional controls, such as democratic political institutions and population, does not compromise the results. We also excluded hydroelectricity projects from the sample. Hydroelectricity projects account for more than $25 \%$ of our sample (1,362 projects), ${ }^{23}$ and they often rely on mature energy technologies, with less need for technology transfer. Since this could induce bias, we estimated our models excluding hydroelectricity projects. The results remain virtually unchanged. Similarly, we dropped all CDM projects

\footnotetext{
${ }^{23}$ This number refers to our complete sample. For our models, the loss of observations ranges from about $16 \%$ in model (2) to about 33\% in model (6).
} 
that focus on energy conservation by increasing energy efficiency. ${ }^{24}$ Our dataset contains 680 such projects (about $13 \%$ of our sample), which are generally technology intensive and could unduly affect our results. However, we find that excluding this specific project type leaves our substantive conclusions intact. This corroborates our analysis against concerns that our renewable project dummy is too coarse of a measure.

Similarly, we excluded all canceled projects from our sample. Since canceled projects are presumably of inferior quality, it is important that they do not drive our results. We classified a project as "canceled" if it was withdrawn by the project developer (4 projects), rejected by the CDM's Executive Board (36 projects), or not validated by the CDM's Designated Operational Entities (37 projects). The results are robust.

To examine possible nonlinearities and selection on observables, we also implemented a matching analysis (Iacus, King, and Porro, 2012). Specifically, we ensured that the distribution of renewable and nonrenewable projects was balanced across three key covariates: small versus large projects, unilateral versus bilateral projects, and the host country's lagged corruption levels. ${ }^{25}$ We found that our dataset was highly balanced to begin with, and the exclusion of only 11 projects resulted in almost perfect balance, with virtually no change in the results.

Another important set of robustness tests focused on the interaction between the renewable project type and additional covariates other than a country's GDP. To analyze these interactions, we replicated our models, but included several extra interaction terms. In separate models, we specifically interacted renewable project type with the small project dummy, the unilateral project dummy, corruption, democracy, and population. ${ }^{26}$ Throughout, the interaction between renewables and GDP continued to have a large and negative coefficient. The extra interactions had weak or inconsistent effects, except that high corruption levels increased the difference in technology transfer between renewable and non-renewable projects. This is broadly consistent with our expectations: in corrupt countries, the risk of intellectual property theft is probably higher than in non-corrupt states.

The GDP measure has another possible problem: perhaps large economies simply do not need foreign technology for renewable energy. We implemented two more models with extra interactions. First, we

\footnotetext{
${ }^{24}$ For our purposes we aggregate demand and supply side projects on energy efficiency, which are separately coded in the CDM/JI Pipeline Database.

${ }^{25}$ See the online appendix for a discussion of how these covariates were chosen for matching.

${ }^{26}$ These factors may differentially condition technology transfer for renewable and non-renewable projects, but since we do not expect the effect of these factors to depend on GDP, we did not include complex triple interactions.
} 
interacted renewable project type with a count of the country's filings of renewable energy patents with the Patent Cooperation Treaty in a given year. ${ }^{27}$ This measure reflects domestic innovation capacity. While we find that patents do modestly reduce the need for technology transfer, our main finding concerning the role of GDP remains unchanged. This suggests that in regard to absorptive capacity, domestic innovation per se is not the defining factor. Instead, the internal market and ability to manufacture are relevant. This is not altogether surprising, given that highly innovative countries may simply not need any foreign technology transfers.

Second, we interacted renewable project type with logarithmized domestic renewable electricity generation capacity, so as to account for domestic experience with renewable energy. ${ }^{28}$ A negative effect was found. The results on the interactive effect of GDP are mostly robust, except for the models without China. This suggests that renewable electricity capacity plays an important role, thought it is hard to say why because growth in renewable electricity capacity is driven by economic growth in developing countries. In any case, this finding calls for further research on how exactly absorptive capacity and other factors affect technology transfer of renewable energy technology.

Yet another test pertained to the potentially coarse measure of GDP for absorptive capacity. To alleviate this concern, we replace our GDP variable with the number of international patents as a more "direct" measure of absorptive capacity. ${ }^{29}$ Our robustness check shows that the interaction effect is always negative: technology transfer decreases for increasing levels of absorptive capacity.

We also examined differences between transfers of equipment and knowledge. Specifically, we estimated our models while excluding all cases of equipment and knowledge transfer, respectively. Our results were fully robust for transfers of equipment but not for knowledge. On the one hand, this is driven by the fact that knowledge transfers are rare: among thousands of projects, there are only approximately 200 projects that feature knowledge transfer. On the other hand, there is also a substantive explanation: in practice, knowledge transfer usually means that foreign engineers visit the host country to train workers. By deploying its own engineers, a foreign inventor can strictly regulate exactly what knowledge is transferred. Indeed, reverse

\footnotetext{
${ }^{27}$ See http://stats.oecd.org/Index.aspx?DatasetCode=PATS_IPC. Accessed on April 18, 2012.

${ }^{28}$ The data are from the United States Energy Information Administration. See http://205.254.135.7/cfapps/ ipdbproject/IEDIndex3. cfm?tid=2\&pid=2\&aid=7 and select "Total Non-Hydroelectric Renewables". Accessed on April 18, 2012. To avoid losing data, the value of this variable is lagged by two years.

${ }^{29}$ See http://stats.oecd.org/Index.aspx?DatasetCode=PATS_IPC. Accessed on April 18, 2012.
} 
engineering is not an issue at all when knowledge is transferred. Thus, it is substantively meaningful that our results are driven by equipment transfers.

\section{Conclusion}

There is little disagreement on the importance of technology transfer for sustainable development. Unless developing countries can gain access to advanced clean technology, they are faced with difficult tradeoffs between slowing economic growth and allowing environmental deterioration, with potential for truly disastrous consequences. Ideally, access to advanced clean technology would allow developing countries to increase their wellbeing while holding environmental costs at acceptable levels. Alas, we have found that technology transfer to developing countries presents major difficulties.

Our theoretical contribution lies in the presentation of an accessible and flexible game-theoretic model of technology transfer decisions in the North-South context. The model highlights the importance of interactive effects: the decision to transfer a commercially promising technology is fundamentally different from the decision to transfer a less valuable technology. The equilibrium analysis suggests that the interaction between technology characteristics and the host country's absorptive capacity is central to understanding and explaining technology transfer outcomes.

Our empirical analysis of technology transfer under the Kyoto Protocol's CDM suggests that the largest and economically most dynamic developing countries rarely benefit from transfer of the most commercially valuable technologies. Specifically, they rarely obtain foreign technologies to promote the production of renewable energy. Analytically, we interpret this finding as suggesting that foreign innovators hesitate to transfer advanced technologies to countries that hold potential for competing in global markets for renewable energy technologies.

These findings have implications for scholarship on international institutions and sustainable development. Our findings suggest that if international institutions are to promote technology transfer, they must find ways to enable more effective contracts between foreign innovators and host countries. These contracts must ensure that host countries gain access to advanced technologies, and this requires that foreign innovators are duly compensated for providing these advanced technologies. Albeit simple, our model offers a flexible strategic foundation for further analyses of the issue. By emphasizing interactions between inventors 
and project developers, we can shed light on the considerations that underpin technology transfer.

For students of sustainable development, the findings are also troubling. According to our findings, advanced clean technologies are not available for those host countries that face the most urgent environmental challenges: the rapidly industrializing ones, such as China and India. If foreign investors worry about the negative consequences of providing China and India with advanced technologies, then China and India cannot benefit from these advanced technologies to combat environmental deterioration. One encouraging trend that may help these countries is their increased ability to innovate on their own: today, both China and India are emerging as new sources of advanced clean technologies. In the light of our findings, this trend is an important one.

Our results also call for new theoretical and empirical research. From a theoretical perspective, it is important to examine the optimal design of technology transfer contracts, especially in the shadow of the kinds of commitment problems highlighted in this article. What types of contracts may we expect to see given the threats to competitiveness that technology transfer presents, and is there any way to improve the environmental performance of these contracts? Empirically, our findings also raise several new questions. One interesting question is why technology transfer under the CDM is decreasing. Is this because the need for importing advanced technology is decreasing, or is it because foreign innovators have burned their fingers and learned not to supply advanced technologies to competitors? These and other similar questions open exciting opportunities for systematic empirical research. 


\section{References}

Ai, Chunrong, and Edward C. Norton. 2003. "Interaction Terms in Logit and Probit Models." Economics Letters 80 (1): 123-129.

Beck, Nathaniel, Jonathan N. Katz, and Richard Tucker. 1998. "Taking Time Seriously: Time-SeriesCross-Section Analysis with a Binary Dependent Variable." American Journal of Political Science 42 (4): $1260-1288$.

Berry, William D., Jacqueline H. R. DeMeritt, and Justin Esarey. 2010. "Testing for Interaction in Binary Logit and Probit Models: Is a Product Term Essential?" American Journal of Political Science 54 (1): 248-266.

Brambor, Thomas, William Roberts Clark, and Matt Golder. 2006. "Understanding Interaction Models: Improving Empirical Analyses.” Political Analysis 14 (1): 63-82.

Brewer, Thomas L. 2008. "Climate Change Technology Transfer: A New Paradigm and Policy Agenda." Climate Policy 8 (5): 516-526.

Carter, David, B., and Curtis S. Signorino. 2010. "Back to the Future: Modeling Time Dependence in Binary Data." Political Analysis 18 (3): 271-292.

Chamberlain, Gary. 1980. "Analysis of Covariance with Qualitative Data." The Review of Economic Studies 47 (1): 225-238.

Cheibub, José Antonio, Jennifer Gandhi, and James Raymond Vreeland. 2010. "Democracy and Dictatorship Revisited." Public Choice 143 (1-2): 67-101.

Dechezleprêtre, Antoine, Matthieu Glachant, and Yann Ménière. 2008. "The Clean Development Mechanism and the International Diffusion of Technologies: An Empirical Study.” Energy Policy 36 (4): 12731283.

Gallagher, Kelly Sims. 2006. "Limits to Leapfrogging in Energy Technologies? Evidence from the Chinese Automobile Industry.” Energy Policy 34 (4): 383-394.

Goenner, Cullen F. 2010. "From Toys to Warships: Interdependence and the Effects of Disaggregated Trade on Militarized Disputes." Journal of Peace Research 47 (5): 547-559.

Grossman, Gene M., and Elhanan Helpman. 1991. Innovation and Growth in the Global Economy. Cambridge: MIT Press.

Hendrix, Cullen S. 2010. "Measuring State Capacity: Theoretical and Empirical Implications for the Study of Civil Conflict.” Journal of Peace Research 47 (3): 273-285.

Hoekman, Bernard M., Keith E. Maskus, and Kamal Saggi. 2005. "Transfer of Technology to Developing Countries: Unilateral and Multilateral Policy Options.” World Development 33 (10): 1587-1602.

Iacus, Stefano M., Gary King, and Giuseppe Porro. 2012. "Causal Inference without Balance Checking: Coarsened Exact Matching.” Political Analysis 20 (1): 1-24. 
Keller, Wolfgang. 1996. "Absorptive Capacity: On the Creation and Acquisition of Technology in Development.” Journal of Development Economics 49 (1): 199-227.

Keller, Wolfgang. 2004. “International Technology Diffusion.” Journal of Economic Literature 42 (3): $752-$ 782.

Lewis, Joanna I. 2007. "Technology Acquisition and Innovation in the Developing World: Wind Turbine Development in China and India." Studies in Comparative International Development 42 (3-4): 208-232.

Lewis, Joanna I., and Ryan H. Wiser. 2007. "Fostering a Renewable Energy Technology Industry: An International Comparison of Wind Industry Policy Support Mechanisms.” Energy Policy 35 (3): 18441857.

Lütken, Søren Ender, and Axel Michaelowa. 2008. Corporate Strategies and the Clean Development Mechanism: Developing Country Financing for Developed Country Commitments? Northampton: Edward Elgar.

Mani, Muthukumara, and David Wheeler. 1998. "In Search of Pollution Havens? Dirty Industry in the World Economy, 1960 to 1995.” Journal of Environment and Development 7 (3): 215-247.

Maskus, Keith E. 2000. Intellectual Property Rights in the Global Economy. Washington DC: Institute for International Economics.

Michaelowa, Axel. 2007. "Unilateral CDM: Can Developing Countries Finance Generation of Greenhouse Gas Emission Credits on Their Own?" International Environmental Agreements 7 (1): 17-34.

Ockwell, David G., Ruediger Haum, Alexandra Mallett, and Jim Watson. 2010. "Intellectual Property Rights and Low Carbon Technology Transfer: Conflicting Discourses of Diffusion and Development." Global Environmental Change 20 (4): 729-739.

Park, Walter G. 2008. “International Patent Protection: 1960-2005.” Research Policy 37 (4): 761-766.

Perkins, Richard, and Eric Neumayer. 2009. "Transnational Linkages and the Spillover of EnvironmentEfficiency into Developing Countries." Global Environmental Change 19 (3): 375-383.

Popp, David. 2011. "International Technology Transfer, Climate Change, and the Clean Development Mechanism." Review of Environmental Economics and Policy 5 (1): 131-152.

REN21. 2011. Renewables Global Status Report: 2011 Update. Paris: REN21 Secretariat.

Ringquist, Evan J., and Tatiana Kostadinova. 2005. "Assessing the Effectiveness of International Environmental Agreements: The Case of the 1985 Helsinki Protocol." American Journal of Political Science 49 (1): 86-102.

Saggi, Kamal. 2002. "Trade, Foreign Direct Investment, and International Technology Transfer: A Survey." World Bank Research Observer 17 (2): 191-235.

Schneider, Malte, Andreas Holzer, and Volker H. Hoffmann. 2008. "Understanding the CDM's Contribution to Technology Transfer." Energy Policy 36 (8): 2930-2938.

UNFCCC. 2010. "The Contribution of the Clean Development Mechanism under the Kyoto Protocol." United Nations Framework Convention on Climate Change. 
Wara, Michael W., and David G. Victor. 2008. "A Realistic Policy on International Carbon Offsets.” Stanford University, Program on Energy and Sustainable Development, Working Paper 74.

Ward, Hugh. 2006. "International Linkages and International Sustainability: The Effects of the Regime Network.” Journal of Peace Research 43 (2): 149-166. 


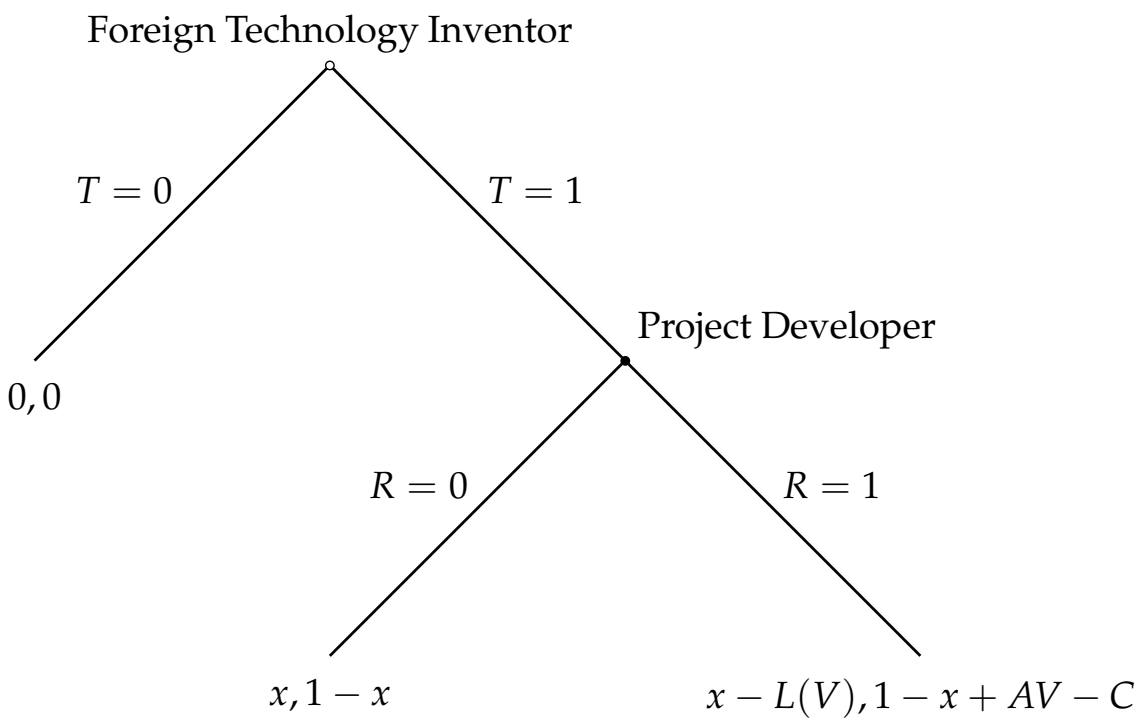

Figure 1: Game tree. In each final node, the first payoff is to the foreign technology investor and the second payoff is to the project developer. 


\section{Technology Transfer over Time}

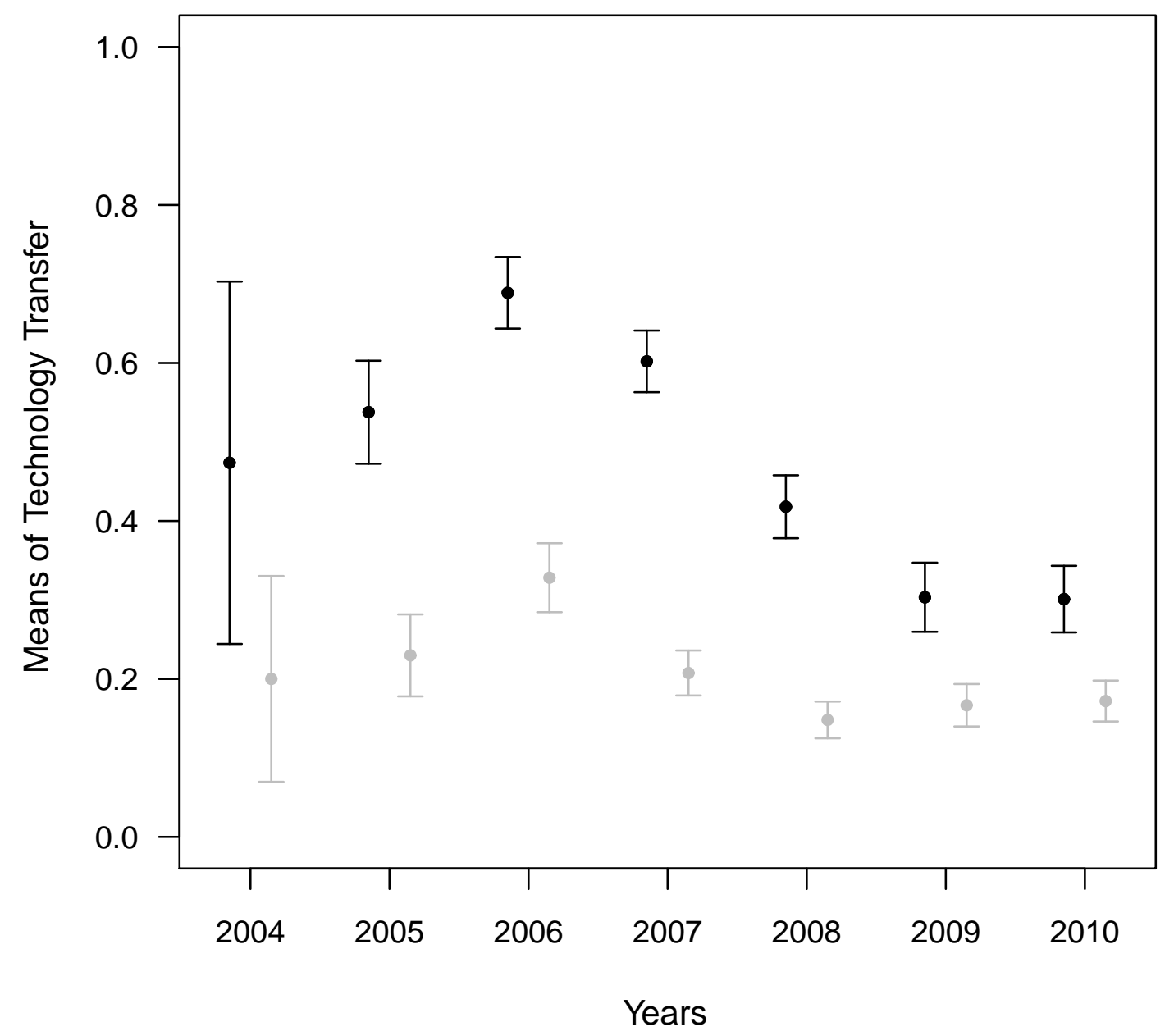

Figure 2: Proportion of projects featuring technology transfer by year, 2004-2010. The black dots denote non-renewable projects; the grey dots denote renewable projects. Error bars indicate $95 \%$ confidence intervals. 


\section{Marginal Effects for Renewable Project Dummy}

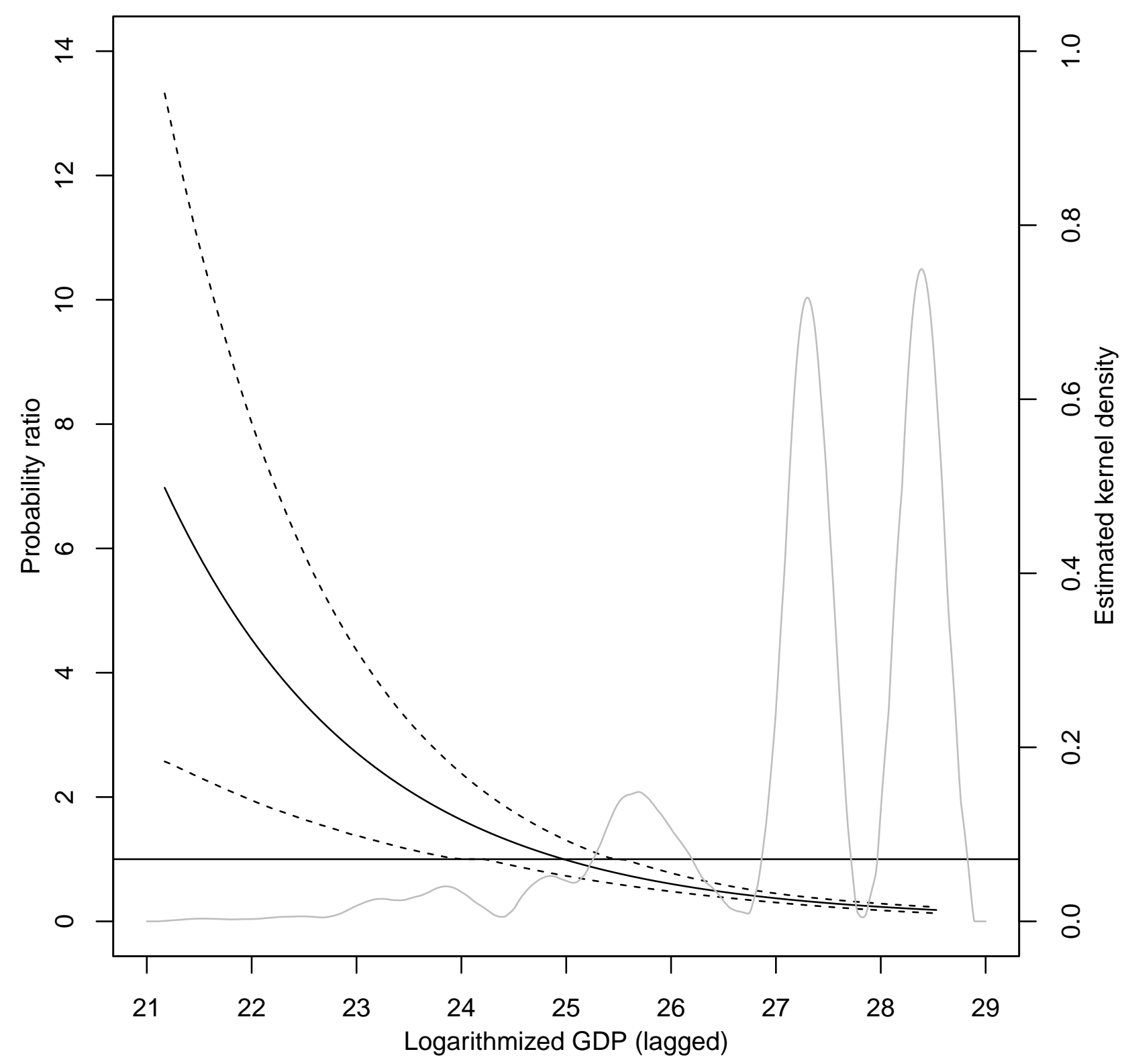

Figure 3: Effect of the renewable project dummy on the probability ratio of technology transfer at different levels of the recipient country's GDP. The solid line shows the simulated mean effect, while dashed lines denote simulated $95 \%$ confidence intervals. The gray line shows the non-parametrically estimated kernel density of the distribution of the data. 


\begin{tabular}{|c|c|c|c|c|c|c|}
\hline \multirow[t]{2}{*}{ \# } & \multirow[t]{2}{*}{ Country } & \multirow[t]{2}{*}{ \# Projects } & \multicolumn{2}{|c|}{ Renewable Projects } & \multicolumn{2}{|c|}{ Other Projects } \\
\hline & & & \# Projects & Tech Transfer & \# Projects & Tech Transfer \\
\hline 1 & China & 2,682 & 1,888 & 0.101 & 794 & 0.418 \\
\hline 2 & India & 1,905 & 1,209 & 0.087 & 696 & 0.193 \\
\hline 3 & Brazil & 478 & 276 & 0.099 & 202 & 0.435 \\
\hline 4 & Mexico & 245 & 39 & 0.652 & 206 & 0.859 \\
\hline 5 & Malaysia & 181 & 54 & 0.657 & 127 & .0563 \\
\hline 6 & Vietnam & 149 & 113 & 0.821 & 36 & 0.363 \\
\hline 7 & Thailand & 141 & 34 & 0.896 & 107 & 0.767 \\
\hline 8 & Indonesia & 139 & 42 & 0.533 & 97 & 0.614 \\
\hline 9 & Korea, Republic & 99 & 61 & 0.571 & 38 & 0.347 \\
\hline 10 & Philippines & 95 & 25 & 0.647 & 70 & 0.442 \\
\hline 11 & Chile & 88 & 49 & 0.513 & 39 & 0.531 \\
\hline 12 & Colombia & 72 & 24 & 0.125 & 48 & 0.461 \\
\hline 13 & Peru & 43 & 13 & 0.347 & 30 & 0.750 \\
\hline 14 & Argentina & 43 & 13 & 0.666 & 30 & 0.680 \\
\hline 15 & Israel & 42 & 8 & 1.000 & 34 & 0.772 \\
\hline 16 & South Africa & 41 & 7 & 0.600 & 34 & 0.760 \\
\hline 17 & Honduras & 35 & 24 & 0.588 & 11 & 0.909 \\
\hline 18 & Sri Lanka & 33 & 24 & 0.588 & 4 & 0.666 \\
\hline 19 & Pakistan & 28 & 5 & 0.750 & 23 & 0.714 \\
\hline 20 & Ecuador & 27 & 18 & 0.500 & 9 & 0.625 \\
\hline
\end{tabular}

Table 1: Top 20 CDM host countries, 2004-2010. The first column shows the total number of CDM projects, while columns two and four show the number of renewable and other CDM projects. The third and the fifth column report the shares of technology transfer in a given country for renewable and other projects separately. 
Full sample: summary statistics

\begin{tabular}{lccccc}
\hline & & & & & \\
& count & mean & sd & $\min$ & $\max$ \\
\hline Technology Transfer & 4358 & 0.31 & 0.46 & 0.00 & 1.00 \\
Renewables & 4358 & 0.61 & 0.49 & 0.00 & 1.00 \\
GDP (log, lagged) & 4358 & 27.21 & 1.36 & 21.17 & 28.53 \\
Renewables x GDP & 4358 & 16.61 & 13.43 & 0.00 & 28.53 \\
Renewable Projects (cum. \#) & 4358 & 22.56 & 22.44 & 0.00 & 69.80 \\
Other Projects (cum. \#) & 4358 & 5.48 & 4.70 & 0.00 & 19.50 \\
Small Project & 4358 & 0.46 & 0.50 & 0.00 & 1.00 \\
Unilateral Project & 4358 & 0.28 & 0.45 & 0.00 & 1.00 \\
Corruption (lagged) & 4358 & 3.81 & 0.51 & 1.50 & 5.50 \\
\hline
\end{tabular}

Sample without China: summary statistics

\begin{tabular}{lccccc}
\hline & & & & & \\
& count & mean & sd & min & $\max$ \\
\hline Technology Transfer & 2604 & 0.38 & 0.48 & 0.00 & 1.00 \\
Renewables & 2604 & 0.52 & 0.50 & 0.00 & 1.00 \\
GDP (log, lagged) & 2604 & 26.43 & 1.25 & 21.17 & 27.43 \\
Renewables x GDP & 2604 & 13.84 & 13.27 & 0.00 & 27.43 \\
Renewable Projects (cum. \#) & 2604 & 14.61 & 19.10 & 0.00 & 69.65 \\
Other Projects (cum. \#) & 2604 & 6.15 & 5.62 & 0.00 & 19.50 \\
Small Project & 2604 & 0.58 & 0.49 & 0.00 & 1.00 \\
Unilateral Project & 2604 & 0.44 & 0.50 & 0.00 & 1.00 \\
Corruption (lagged) & 2604 & 3.68 & 0.62 & 1.50 & 5.50 \\
\hline
\end{tabular}

Sample without India: summary statistics

\begin{tabular}{lccccc}
\hline & & & & & \\
& count & mean & sd & $\min$ & $\max$ \\
\hline Technology Transfer & 3248 & 0.36 & 0.48 & 0.00 & 1.00 \\
Renewables & 3248 & 0.59 & 0.49 & 0.00 & 1.00 \\
GDP (log, lagged) & 3248 & 27.21 & 1.57 & 21.17 & 28.53 \\
Renewables x GDP & 3248 & 16.23 & 13.57 & 0.00 & 28.53 \\
Renewable Projects (cum. \#) & 3248 & 19.81 & 22.67 & 0.00 & 69.80 \\
Other Projects (cum. \#) & 3248 & 4.08 & 3.36 & 0.00 & 13.88 \\
Small Project & 3248 & 0.39 & 0.49 & 0.00 & 1.00 \\
Unilateral Project & 3248 & 0.16 & 0.36 & 0.00 & 1.00 \\
Corruption (lagged) & 3248 & 3.84 & 0.54 & 1.50 & 5.50 \\
\hline
\end{tabular}

Table 2: Summary statistics for the full sample and for samples excluding China and India. The summary statistics are based on the conditional fixed effects models. 
Main regression results

\begin{tabular}{|c|c|c|c|c|c|c|c|c|c|}
\hline & $\begin{array}{c}(1) \\
\text { Model }\end{array}$ & $\begin{array}{c}(2) \\
\text { Model }\end{array}$ & $\begin{array}{c}(3) \\
\text { Model }\end{array}$ & $\begin{array}{c}(4) \\
\text { Model }\end{array}$ & $\begin{array}{c}(5) \\
\text { Model }\end{array}$ & $\begin{array}{c}(6) \\
\text { Model }\end{array}$ & $\begin{array}{c}(7) \\
\text { Model }\end{array}$ & $\begin{array}{c}(8) \\
\text { Model }\end{array}$ & $\begin{array}{c}(9) \\
\text { Model }\end{array}$ \\
\hline Renewables & $\begin{array}{c}11.73^{* * *} \\
(1.49)\end{array}$ & $\begin{array}{c}6.25^{* * *} \\
(2.02)\end{array}$ & $\begin{array}{c}11.61^{* * *} \\
(1.49)\end{array}$ & $\begin{array}{c}12.65^{* * *} \\
(1.62)\end{array}$ & $\begin{array}{c}7.75^{* * *} \\
(2.24)\end{array}$ & $\begin{array}{c}12.83^{* * *} \\
(1.64)\end{array}$ & $\begin{array}{c}8.46^{* * *} \\
(1.13)\end{array}$ & $\begin{array}{c}6.26^{* * *} \\
(1.66)\end{array}$ & $\begin{array}{c}8.37^{* * *} \\
(1.14)\end{array}$ \\
\hline GDP (log, lagged) & $\begin{array}{c}-2.59^{* * *} \\
(1.00)\end{array}$ & $\begin{array}{c}4.16^{* * *} \\
(1.52)\end{array}$ & $\begin{array}{c}-4.11^{* * *} \\
(1.04)\end{array}$ & $\begin{array}{c}-4.77^{* *} \\
(2.27)\end{array}$ & $\begin{array}{c}0.58 \\
(2.75)\end{array}$ & $\begin{array}{c}-6.10^{* *} \\
(2.39)\end{array}$ & $\begin{array}{c}0.62^{* * *} \\
(0.17)\end{array}$ & $\begin{array}{c}0.55^{* * *} \\
(0.20)\end{array}$ & $\begin{array}{c}0.39^{* *} \\
(0.19)\end{array}$ \\
\hline Renewables x GDP & $\begin{array}{c}-0.47^{* * *} \\
(0.05)\end{array}$ & $\begin{array}{c}-0.26^{* * *} \\
(0.08)\end{array}$ & $\begin{array}{c}-0.47^{* * *} \\
(0.06)\end{array}$ & $\begin{array}{c}-0.51^{* * *} \\
(0.06)\end{array}$ & $\begin{array}{c}-0.31^{* * *} \\
(0.08)\end{array}$ & $\begin{array}{c}-0.52^{* * *} \\
(0.06)\end{array}$ & $\begin{array}{c}-0.34^{* * *} \\
(0.04)\end{array}$ & $\begin{array}{c}-0.25^{* * *} \\
(0.06)\end{array}$ & $\begin{array}{c}-0.34^{* * *} \\
(0.04)\end{array}$ \\
\hline Renewable Projects (cum. \#) & & & & $\begin{array}{c}0.00 \\
(0.01)\end{array}$ & $\begin{array}{c}0.03^{* *} \\
(0.01)\end{array}$ & $\begin{array}{c}0.00 \\
(0.01)\end{array}$ & $\begin{array}{c}0.00 \\
(0.00)\end{array}$ & $\begin{array}{l}0.01^{*} \\
(0.01)\end{array}$ & $\begin{array}{l}-0.00 \\
(0.00)\end{array}$ \\
\hline Other Projects (cum. \#) & & & & $\begin{array}{l}-0.04 \\
(0.03)\end{array}$ & $\begin{array}{c}-0.13^{* * *} \\
(0.04)\end{array}$ & $\begin{array}{c}-0.14^{* * *} \\
(0.04)\end{array}$ & $\begin{array}{l}-0.03^{*} \\
(0.02)\end{array}$ & $\begin{array}{c}-0.06^{* * *} \\
(0.02)\end{array}$ & $\begin{array}{c}-0.06^{* * *} \\
(0.02)\end{array}$ \\
\hline Small Project & & & & $\begin{array}{c}-0.69^{* * *} \\
(0.09)\end{array}$ & $\begin{array}{c}-0.41^{* * *} \\
(0.11)\end{array}$ & $\begin{array}{c}-0.78^{* * *} \\
(0.11)\end{array}$ & $\begin{array}{c}-0.43^{* * *} \\
(0.06)\end{array}$ & $\begin{array}{c}-0.23^{* * *} \\
(0.07)\end{array}$ & $\begin{array}{c}-0.52^{* * *} \\
(0.07)\end{array}$ \\
\hline Unilateral Project & & & & $\begin{array}{l}-0.23^{*} \\
(0.12)\end{array}$ & $\begin{array}{c}-0.44^{* * *} \\
(0.12)\end{array}$ & $\begin{array}{l}-0.19 \\
(0.15)\end{array}$ & $\begin{array}{c}-0.15^{* *} \\
(0.07)\end{array}$ & $\begin{array}{c}-0.27^{* * *} \\
(0.08)\end{array}$ & $\begin{array}{l}-0.05 \\
(0.09)\end{array}$ \\
\hline Corruption (lagged) & & & & $\begin{array}{c}-0.49^{* * *} \\
(0.11)\end{array}$ & $\begin{array}{c}-0.32^{* * *} \\
(0.11)\end{array}$ & $\begin{array}{l}-0.12 \\
(0.13)\end{array}$ & $\begin{array}{l}-0.08 \\
(0.07)\end{array}$ & $\begin{array}{l}-0.09 \\
(0.07)\end{array}$ & $\begin{array}{c}0.03 \\
(0.07)\end{array}$ \\
\hline Democracy (lagged) & & & & & & & $\begin{array}{c}-0.41^{* *} \\
(0.19)\end{array}$ & $\begin{array}{l}-0.20 \\
(0.21)\end{array}$ & $\begin{array}{l}-0.23 \\
(0.19)\end{array}$ \\
\hline Population (log, lagged) & & & & & & & $\begin{array}{c}-0.44^{* * *} \\
(0.14)\end{array}$ & $\begin{array}{c}-0.50^{* * *} \\
(0.16)\end{array}$ & $\begin{array}{l}-0.23 \\
(0.16)\end{array}$ \\
\hline Internet Users & & & & & & & $\begin{array}{c}-0.03^{* * *} \\
(0.01)\end{array}$ & $\begin{array}{c}-0.02^{* *} \\
(0.01)\end{array}$ & $\begin{array}{l}-0.01 \\
(0.01)\end{array}$ \\
\hline Pct Industry GDP (lagged) & & & & & & & $\begin{array}{c}0.03^{* * *} \\
(0.01)\end{array}$ & $\begin{array}{l}0.02^{* *} \\
(0.01)\end{array}$ & $\begin{array}{l}0.02^{*} \\
(0.01)\end{array}$ \\
\hline Investment Profile (lagged) & & & & & & & $\begin{array}{c}0.12^{* * *} \\
(0.05)\end{array}$ & $\begin{array}{l}0.08^{*} \\
(0.05)\end{array}$ & $\begin{array}{c}0.11^{* *} \\
(0.05)\end{array}$ \\
\hline Inward FDI (lagged) & & & & & & & $\begin{array}{c}-0.00^{* * *} \\
(0.00)\end{array}$ & $\begin{array}{l}-0.00 \\
(0.00)\end{array}$ & $\begin{array}{c}-0.00^{* * *} \\
(0.00)\end{array}$ \\
\hline Patents Count (log, lagged) & & & & & & & $\begin{array}{c}0.03 \\
(0.08)\end{array}$ & $\begin{array}{c}0.06 \\
(0.08)\end{array}$ & $\begin{array}{c}0.13 \\
(0.08)\end{array}$ \\
\hline Renewable Patents & & & & & & & $\begin{array}{l}-0.00^{*} \\
(0.00)\end{array}$ & $\begin{array}{c}0.01 \\
(0.01)\end{array}$ & $\begin{array}{c}-0.01^{* *} \\
(0.00)\end{array}$ \\
\hline IPP Patents Index & & & & & & & $\begin{array}{l}-0.32 \\
(0.21)\end{array}$ & $\begin{array}{l}-0.46^{*} \\
(0.24)\end{array}$ & $\begin{array}{l}-0.30 \\
(0.21)\end{array}$ \\
\hline Time Polynomial & Yes & Yes & Yes & Yes & Yes & Yes & Yes & Yes & Yes \\
\hline $\begin{array}{l}\text { Observations } \\
\text { Pseudo } R^{2}\end{array}$ & $\begin{array}{l}4894 \\
0.105\end{array}$ & $\begin{array}{l}2914 \\
0.051\end{array}$ & $\begin{array}{r}3648 \\
0.118\end{array}$ & $\begin{array}{l}4358 \\
0.132\end{array}$ & $\begin{array}{l}2604 \\
0.074\end{array}$ & $\begin{array}{l}3248 \\
0.154\end{array}$ & 4076 & 2322 & 2966 \\
\hline
\end{tabular}

Standard errors in parentheses

Dependent Variable: Technology Transfer Dummy.

Models (2),(5), and (8) exclude China. Models (3),(6), and (9) exclude India.

${ }^{*} p<0.10,{ }^{* *} p<0.05,{ }^{* * *} p<0.01$

Table 3: Regression results from conditional fixed effects logit models and random effects probit models. 